\title{
8
}
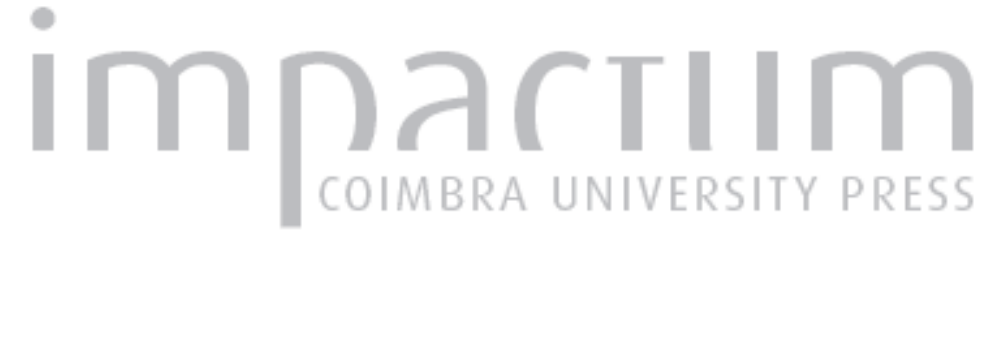

\section{Imigração e territórios em mudança: teoria e prática(s) do modelo de atração- repulsẵo numa região de baixas densidades}

\author{
Autor(es): $\quad$ Castro, Fátima Velez de
}
Publicado por: Faculdade de Letras da Universidade de Coimbra, Departamento de Geografia

URL

persistente:

URI:http://hdl.handle.net/10316.2/30222

DOI:

DOI:http://dx.doi.org/10.14195/0871-1623_31_20

\section{Accessed : $\quad$ 26-Apr-2023 11:33:36}

A navegação consulta e descarregamento dos títulos inseridos nas Bibliotecas Digitais UC Digitalis, UC Pombalina e UC Impactum, pressupõem a aceitação plena e sem reservas dos Termos e Condições de Uso destas Bibliotecas Digitais, disponíveis em https://digitalis.uc.pt/pt-pt/termos.

Conforme exposto nos referidos Termos e Condições de Uso, o descarregamento de títulos de acesso restrito requer uma licença válida de autorização devendo o utilizador aceder ao(s) documento(s) a partir de um endereço de IP da instituição detentora da supramencionada licença.

Ao utilizador é apenas permitido o descarregamento para uso pessoal, pelo que o emprego do(s) título(s) descarregado(s) para outro fim, designadamente comercial, carece de autorização do respetivo autor ou editor da obra.

Na medida em que todas as obras da UC Digitalis se encontram protegidas pelo Código do Direito de Autor e Direitos Conexos e demais legislação aplicável, toda a cópia, parcial ou total, deste documento, nos casos em que é legalmente admitida, deverá conter ou fazer-se acompanhar por este aviso.

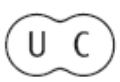




\title{
Imigração e territórios em mudança. Teoria e prática(s) do modelo de atração-repulsão numa região de baixas densidades
}

\author{
Fátima Velez de Castro \\ Departamento de Geografia e Centro de Estudos de Geografia e Ordenamento do Território (CEGOT). Faculdade de Letras da Universidade de Coimbra. \\ velezcastro@fl.uc.pt
}

\section{Resumo:}

Os estudos pioneiros de Ravenstein $(1876,1889)$ tiveram um carácter determinante na construção do quadro teórico associado às migrações. Ao desenvolver os princípios do modelo de atração-repulsão, o autor destaca o papel da dinâmica territorial na estruturação do projeto migratório dos indivíduos, cuja decisão de se deslocarem do local de origem para um determinado destino estará relacionada com a percepção positiva ou negativa face a determinados aspetos de ambos os lugares. Significa que, por um lado, os migrantes serão influenciados pela existência de fatores repulsivos existentes no território de partida; por outro, a escolha do território de destino estará condicionada pela existência de fatores atrativos, nomeadamente de cariz económico, laboral e social. Lee (1969) continua o trabalho de Ravenstein, embora the faça algumas críticas, considerando a existência de obstáculos intervenientes e de fatores pessoais como aspetos determinantes a considerar na decisão de migrar. Assim, parte-se do princípio que há uma tendência para que os migrantes se desloquem de áreas pouco povoadas para áreas de maior concentração humana; de regiões de baixas densidades para regiões dinâmicas do ponto de vista económico e social; de territórios pobres e pouco desenvolvidos para territórios com um maior nível de desenvolvimento. Porém, coloca-se em causa a linearidade do processo: será que as regiões consideradas repulsivas não podem revelar dinâmicas diferenciadas (neste caso positivas) face a distintas realidades migratórias?

Com o objetivo de clarificar a questão, procurar-se-ão discutir os princípios estruturantes do modelo de atraçãorepulsão de Ravenstein, tendo em conta não só a análise crítica de Lee, como também os pressupostos defendidos pelas principais teorias e modelos migratórios, numa perspetiva de complementaridade. Além desta construção teórica, será analisado o estudo de caso de um território português de baixas densidades, com características territoriais potencialmente repulsivas, na sub-região do Alto Alentejo. 0 interesse de investigação nesta área geográfica está relacionado com o facto de, ao longo da última década, se ter verificado uma renovada dinâmica territorial à escala local, gerada pela presença de grupos de imigrantes que aí residem e trabalham. A partir da compreensão das motivações de deslocação destes indivíduos entre os dois pólos migratórios (origem e destino), tentar-se-á discutir em termos práticos, a validade e as fragilidades do modelo migratório em causa.

Palavras-chave: Modelo de atração-repulsão. Migrações. Território. Baixas densidades.

\section{Résumé:}

Immigration et territoires en changement. Théories et pratique(s) du modèle d'attraction-répulsion dans une région à baisses densités

Les études pionnières de Ravenstein $(1876,1889)$ ont apporté une empreinte déterminante en ce qui concerne la construction du cadre théorique qu'on associe aux migrations. En développant les principes du modèle d'attractionrépulsion, l'auteur met en évidence le rôle de la dynamique territoriale dans la structuration du projet migratoire des individus, dont la décision de se déplacer du point d'origine vers une certaine destination serait en rapport avec la perception positive ou négative devant certains aspects de tous les deux lieux. Cela veut dire que, d'un côté, les migrants seront influencés par l'existence de facteurs répulsifs lesquels existent dans le territoire d'origine; de l'autre, le choix du territoire de destination sera conditionné par l'existence de facteurs attractifs, notamment d'aspect économique, de travail et sociale. Lee (1969) continue le travail de Ravenstein, quoiqu'il lui fasse quelques critiques, tout en considérant l'existence d'obstacles qu'interviennent et des facteurs personales en tant qu'aspects déterminantes à considérer pour la décision de migrer. De cette façon, on est d'accord qu'il y a une tendance pour que les migrants se déplacent de régions peu peuplées vers des régions d'une concentration humaine plus forte; de régions à baisses densités vers des régions plus dynamiques du point de vue économique et sociale; de territoires pauvres et peu développés vers des territoires qui profitent d'un niveau de développement plus haut. Cependant, on met en cause la 
linéarité du procédé: les régions jugées répulsives ne peuvent-elles pas révéler des dynamiques différenciées (dans ce cas positives) par rapport à de réalités migratoires différentes?

Ayant pour but rendre plus clair cette question, on cherchera à débattre les principes structurants du modèle d'attraction-répulsion de Ravenstein, tout en tenant compte pas seulement de l'analyse critique de Lee, mais aussi les prémisses défendues par les plus importantes théories et modèles migratoires, dans une perspective de complémentarité. Outre cette construction théorique, on analysera l'étude de cas d'un territoire portugais à baisses densités, lequel possède de caractéristiques territoriales potentiellement répulsives, dans la sous-région Alto Alentejo. L'intérêt de recherche dans cette région géographique est lié au fait qu'on a constaté, durant la dernière décennie, une dynamique territoriale à l'échelle locale renouvelée, générée par la présence de groupes d'immigrés qu'y habitent et travaillent. Ayant comme point de départ la compréhension des motivations de déplacement de ces individus entre les deux pôles migratoires (origine et destination), on essayera de débattre, dans des termes pratiques, la validité et les fragilités du modèle migratoire en question.

Mots-clés: Modèle d'attraction-répulsion. Migrations. Territoire. Baisses densités.

\section{Abstract:}

Immigration and changing territories. Theory and practice(s) of the attraction-repulsion model in a low density region

The Pioneer studies by Ravenstein $(1876,1889)$ had a determinant character in the construction of the theoretical Framework associated to migrations. By developing the principles of the attraction-repulsion model, the author highlights the role of the territorial dynamic in structuring the migration process of the individuals, whose decision of moving from the place of origin to a certain destination is connected to the positive or negative perception towards certain aspects of both places. Meaning, on the one hand, that migrants are influenced by the existence of repulsive factors on the departure territory; on the other hand, the choice of the destination territory will be conditioned by the existence of attractive factors, namely in economic, work and social terms. Lee (1969) continues Ravenstein's work, although with some critics, considering the existence of intervening obstacles and personal factors as determinant aspects to be considered in the decision to migrate. Therefore, it is assumed that there is a tendency so that migrants come from sparsely populated areas to places with a larger human concentration; from low density regions to economically and socially dynamic areas; from poor and low development territories to territories with greater levels of development. However, it is questioned the linearity of the process: can the considered repulsive areas reveal different dynamics (in this case, positive dynamics) against opposite migratory realities?

Aiming to clarify the issue, it is intended to discuss the structuring principles of the attraction-repulsion model by Ravenstein, bearing in mind not only the critical analysis by Lee, but also the assumptions defended by the main migration models and theories, in a perspective of complementarity. Besides this theoretical construction, it will be analyzed the case study of a Portuguese low density territory with potentially repulsive characteristics in the Alto Alentejo sub-region. The research interest of this geographical area is related with the fact that, throughout the last decade, a renewed territorial dynamics at a local scale is being verified, generated by the presence of immigrant groups that live and work in this area. From the understanding of the moving motivations of these individuals between these two migration poles (origin and destination), it will be tried to discuss in practical terms the validity and fragility of the migration model in question.

Keywords: Attraction-repulsion model. Migrations. Territory. Low densities. 


\section{Os princípios estruturantes do modelo de atração- repulsão de Ravenstein}

A constituição de um quadro teórico em torno da temática migratória, em muito se deveu ao contributo de Ernest George Ravenstein (1852-1913), cujos estudos sobre a mobilidade da população em Inglaterra e no País de Gales o levou a concluir que não havia aleatoriedade nas escolhas geográficas dos indivíduos. Para provar este pressuposto, baseou-se nos recenseamentos da população britânica (naturalidade e residência, entre 1871 e 1881), tendo ainda analisado dados semelhantes sobre populações da Europa e da América do Norte.

Segundo o autor, a decisão de se migrar de um determinado território para outro, é tomada com base num binómio geográfico em que se consideram as vantagens e desvantagens económicas, laborais, sociais, etc. de residir e trabalhar no local 1 versus o local 2 . Partia-se então do princípio que na origem de uma migração, estariam sempre em destaque a influência de fatores repulsivos do local 1 (por exemplo, desemprego, baixos salários, fracas oportunidades de ascensão profissional ou académica, etc.). Em contraposição, no local 2 o migrante colocaria em evidência fatores atrativos (por exemplo, disponibilidade de emprego, salários elevados, oportunidades de formação profissional e académica, etc.). Rocha-TRINDADE (1995: 73) destaca que as condições identificadas pelos migrantes podem ser de vários tipos, embora geograficamente se valorize o dinamismo económico das áreas urbanas face às áreas rurais de partida. Este princípio foi deci- sivo para a constituição do modelo de atração-repulsão (1876), o qual entende o indivíduo como um ser racional, procurando maximizar os lucros numa lógica de homo economicus (FonseCA, 2005: 72). Neste sentido, destacase a importância da escola neoclássica, que corrobora o pressuposto ao defender que as migrações resultam de decisões racionais, preconizadas por indivíduos que se deslocam tendo como principal objetivo o aumento dos rendimentos. Esta meta seria cumprida através da melhoria dos níveis salariais obtidos no local de destino migratório, daí que os migrantes tenham tendência a se deslocar para locais onde possam beneficiar de mais e melhores oportunidades laborais (ARANGo, 2004: 19).

As migrações resultariam assim de uma simples condição de escolha da positividade territorial versus negatividade territorial, onde o migrante se constitui como um ator relativamente passivo perante uma realidade demasiado linear, embora the seja reconhecido a capacidade de equacionar as vantagens e desvantagens decorrentes dos processos e dos espaços.

Ravenstein consolida os seus estudos, sistematizando um conjunto de princípios - as "Leis da Migração". De ter em conta que as leis enunciadas são de caráter empírico, sem fundamentação teórica, o que gerou e gera críticas entre os académicos. Contudo não deixa de ser meritório a observação de princípios que, embora discutíveis, se constituíram como base analítica para posteriores teorias migratórias.

As Leis da Migração, com forte influência territorial, revelam três tipos de abordagem, que se relacionam entre si:

Quadro I

As leis das migração de Ravenstein: uma abordagem crítica

\begin{tabular}{|c|c|}
\hline Leis da Migração, de Ravenstein & Análise crítica \\
\hline Muitos migrantes deslocam-se para curtas distâncias & $\begin{array}{l}\text { Os movimentos transoceânicos (Europa-América) tiveram bastante importância } \\
\text { porque envolveram um número substancial de migrantes }\end{array}$ \\
\hline $\begin{array}{l}\text { O volume das migrações aumenta com o desenvolvimento da indústria } \\
\text { e do comércio }\end{array}$ & Pode não acontecer em países receptores com políticas migratórias restritivas \\
\hline $\begin{array}{l}\text { A direção da migração é fundamentalmente das áreas agrícolas para as } \\
\text { industriais (rural-urbana) }\end{array}$ & $\begin{array}{l}\text { Também pode tomar outras direções (urbana-rural, por exemplo no caso das } \\
\text { migrações séniores do Norte/Centro para o Sul da Europa) }\end{array}$ \\
\hline $\begin{array}{l}\text { As migrações de longa distância dirigem-se para os principais centros } \\
\text { comerciais e industriais }\end{array}$ & As de curta distância também se podem dirigir para esses centros \\
\hline A migração processa-se por etapas & No caso de migrações forçadas (refugiados e deslocados), tal pode não acontecer \\
\hline Todas as correntes migratórias geram uma contra corrente & Questão relativa da "totalidade" das migrações assumida pelo autor \\
\hline A população natural das cidades migra menos que a dos campos & $\begin{array}{l}\text { Princípio relativizado pela circulação migratória de quadros com elevadas qualifi- } \\
\text { cações profissionais, oriundos de áreas urbanas }\end{array}$ \\
\hline $\begin{array}{l}\text { As mulheres têm maior mobilidade interna qua os homens, mas os } \\
\text { homens aventuram-se a migrar para locais mais distantes }\end{array}$ & $\begin{array}{l}\text { Hoje em dia há tendências para uma equiparação do género, embora em algumas } \\
\text { nacionalidades prevaleçam os fluxos masculinizados (por exemplo, países árabes) }\end{array}$ \\
\hline $\begin{array}{l}\text { Os migrantes são geralmente adultos. As famílias raramente emigram } \\
\text { para grandes distâncias }\end{array}$ & $\begin{array}{l}\text { Podem migrar adultos mais velhos (por exemplo, migrações séniores). As famílias } \\
\text { podem migrar para grandes distâncias (por exemplo, o caso das migrações tran- } \\
\text { satlânticas) }\end{array}$ \\
\hline $\begin{array}{l}\text { As grandes cidades crescem mais à custa das migrações do que do } \\
\text { crescimento natural }\end{array}$ & Poder-se-á aplicar esse princípio a todas as áreas da cidade? \\
\hline As principais causas das migrações são de ordem económica & $\begin{array}{l}\text { As teorias das migrações defendem outros fatores intervenientes na decisão de } \\
\text { migrar (por exemplo, aquisição de formação académica) }\end{array}$ \\
\hline
\end{tabular}

Adaptado de Fonseca (2005) e Velez de Castro (2008). 
a) Geográfica - distância e direção dos fluxos, relação entre os espaços rurais e urbanos, movimentos de contra corrente;

b) Social - tipologia dos fluxos associada ao género e à constituição familiar (agregados);

c) Económica - motivações (possivelmente) laborais para a deslocação, importância da indústria e do comércio como setores de atração dos migrantes.

Figueiredo (2005: 23, 27), cita Petersen (1958), que destaca a necessidade de distinção das motivações dos migrantes face às causas sociais das migrações, quando se consideram os aspetos repulsivos. Estes fatores teriam por base dois argumentos: um defendendo que seriam os trabalhadores dos setores com menor grau de desenvolvimento aqueles que apresentariam um maior incentivo para emigrar; outro que justificava as migrações com base nas disparidades económicas entre países, tal como preconiza a escola neoclássica. Além disso, o modelo de atraçãorepulsão acaba por não explicar alguns determinantes de caráter "micro" nas migrações (por exemplo, a diferente propensão a migrar, por parte de indivíduos com caraterísticas semelhantes), nem "macro" (migrações para áreas com muita população onde poderá ser mais difícil obter benefícios, por exemplo devido à concorrência laboral).

No que diz respeito à integração profissional de migrantes dos territórios de destino migratório, a teoria do mercado de trabalho segmentado defende que, de uma forma geral, os estrangeiros tendem a desempenhar funções preteridas pelos autóctones. Encara por isso o mercado de trabalho "dividido" em dois segmentos: um superior, onde as tarefas são mais especializadas, os trabalhadores bem remunerados, sendo evidentes as condições de segurança física e reconhecimento social; um inferior com tarefas indiferenciadas, remunerações mais baixas e em certos casos com um caráter informal do ponto de vista dos direitos sociais. Por isso, o primeiro segmento tende a ser ocupado por nacionais, que acedem com mais facilidade a esses empregos, deixando para os estrangeiros as atividades consideradas menos prestigiantes do ponto de vista social e com menos regalias monetárias.

Ainda no que diz respeito ao modelo de Ravenstein, e embora possa ser criticável o fato deste autor ter determinado leis e pressupostos demasiado lineares e pouco flexíveis quanto aos casos particulares, há que ter em atenção o momento e a realidade em que se baseiam.

Foi nesse sentido que, em 1969, o demógrafo americano Everett LeE introduziu novos elementos no modelo de atração-repulsão de RAVENSTEIN. Embora considere as migrações como um processo impulsionado por fatores atrativos e repulsivos, afirma que se deve ter em conta a existência de obstáculos intervenientes e fatores pessoais que também interferem na decisão de migrar (Velez de Castro, 2008a: 96). No primeiro caso defende que a distância, associada aos custos de deslocação (transporte) e as barreiras físicas (de caráter burocrático), assim como as políticas migratórias, poderão ser impeditivas da deslocação. No segundo, destaca as alterações vividas nas diferentes fases da vida do indivíduo, nomeadamente a idade, a escolaridade, a relação conjugal, entre outros. Entende que a decisão de migrar poderá ser condicionada pela estrutura do agregado familiar, por exemplo se o indivíduo encara a existência de um cônjuge e de filhos como impeditiva ou motivadora para a deslocação. Por um lado, pode pretender que os descendentes frequentem a escola no local de nascimento, perto de uma rede familiar de apoio (avós, etc.), no sentido de manter a identidade cultural "original". Mas por outro, pode entender a migração à escala internacional como uma oportunidade para os filhos dominarem uma segunda língua, terem mais e melhores oportunidades académicas.

Essa escolha esta relacionada com o que o autor denomina de "capacidades", destacando a sensibilidade e a inteligência, que ajudam a compreender que, perante contextos geográficos, sociais e económicos similares, existam indivíduos que migrem enquanto outros optam por não o fazer. A teoria do capital humano destaca o investimento na educação, sobretudo de jovens, como uma forte motivação para as migrações de caráter individual (aposta na formação académica e profissional do próprio migrante) e familiar (importância da educação dos filhos).

Lee evidencia ainda a importância dos contatos e das informações disponibilizadas ao potencial migrante, que se referem ao local de destino. A teoria do capital social ou das redes corrobora tal princípio ao enfatizar a importância do apoio de amigos e familiares imigrados, os quais mitigam os riscos do processo migratório através de ajuda financeira (suportando custos de deslocação), social (integração no mercado de trabalho e na comunidade autóctone) e afetiva (promoção da identidade coletiva, da matriz cultural do território de origem do migrante).

Contudo, PIREs (2003: 70-73) chama a atenção para a parcialidade informativa que poderá estar inerente às redes de entreajuda: "Na maioria dos casos os individuos, mesmo se migram em função de um cálculo racional de custos-benefícios, fazem-no num 
espaço de comparabilidade muito limitado, o que não permite relacionar o seu resultado com o critério da maximização."

Significa que a disponibilidade e a fiabilidade de informação pode-se constituir como um entrave ao sucesso do projeto migratório, pois nem todos têm acesso ou capacidades para compreender e operar com os dados de que dispõem sobre a dinâmica real do território de destino migratório. Assim, geram-se expectativas em torno de uma imagem territorial baseada num "território desejado", que pode não corresponder à realidade (Velez de Castro, 2008b: 39).

LeE (1996: 16-24) repensa ainda as leis enunciadas por Ravenstein e apresenta pressupostos (re)formulados:

a) 0 volume de migrações num território varia com o próprio grau de diversidade apresentado por esse mesmo território;

b) $\mathrm{O}$ volume de migrantes varia conforme a diversidade apresentada por esses mesmos migrantes e com o grau de facilidade/dificuldade em superar os obstáculos do processo migratório;

c) As migrações têm tendência a ocorrer segundo trâmites definidos (desenvolvimento de redes);

d) Por cada corrente migratória com um volume de migrantes significativo, tende-se a desenvolver uma contra corrente;

e) A eficiência do fluxo migratório (rácio entre a corrente e a contracorrente) é maior se os fatores que originaram a migração se alterarem. No caso dos fatores se manterem na origem/destino, a eficiência do fluxo diminui;

f) A eficiência do fluxo migratório aumenta se os obstáculos forem difíceis de ultrapassar;

g) A eficiência de um fluxo migratório varia conforme as condições económicas, ou seja, aumenta em períodos de prosperidade económica e diminui em tempo de crise;

h) A migração é seletiva: pode ser positiva se os migrantes responderem com sucesso às solicitações do local de acolhimento, ou negativa no caso contrário;

i) 0 processo de seleção positiva aumenta com a dificultação dos obstáculos; da vida;

j) Há mais propensão para migrar em certas fases

k) As caraterísticas dos migrantes tendem a ser um intermédio entre as caraterísticas da população do local de origem e da população do local de destino.

0 autor destaca a dinâmica dos territórios, no que diz respeito à diversidade e à influência dos fatores positivos e negativos como determinantes da decisão de migrar. Além disso atribui um caráter mais dinâmico à potencial população migrante, na forma como responde às condicionantes da migração, como supera os obstáculos, ou como se adapta à dinâmica do local e da comunidade de acolhimento. O processo de seleção acaba por ser determinado pelas próprias escolhas, caraterísticas e determinação dos indivíduos, que também se relaciona com a conjuntura económica.

De realçar dois aspetos: o primeiro é que nem sempre em momentos de crise as migrações abrandam; o segundo é que os obstáculos acabam por ser contornados especialmente em momentos de grandes pressões, através do estabelecimento de redes ilegais as quais interferem no processo migratório não tanto por se ultrapassar as condicionantes legais, mas antes desenvolvendo no migrante uma falsa sensação de que efetivamente realizou a migração contornando os obstáculos, quando na verdade a imigração ilegal "adia" as condicionantes.

A seletividade que LEE enfatiza também se vê comprometida por este pressuposto. A existência de redes sociais "legais" que o autor reconhece, ajudam os migrantes a superar os obstáculos de forma legal e positiva. Significa que as relações entre os migrantes e os membros emigrados da comunidade de acolhimento são importantes pois também anulam a questão da seletividade, se forem consideradas como canais onde as várias etapas são bem conhecidas pelos seus membros. Estes conseguem, com mais facilidade, dar resposta às diversas dificuldades que o pretenso migrante enfrenta, não só porque já vivenciaram os obstáculos, mas também porque se movem com facilidade no território de acolhimento através das relações estabelecidas com a comunidade autóctone/outros estrangeiros.

De destacar ainda a aproximação de LEE à teoria dos sistemas migratórios, ao associar a intensificação e a desaceleração dos fluxo migratórios às circunstância do contexto económico. Porém é de ter em conta que alguns fatores pessoais identificados pelo autor, em especial as capacidades (sensibilidade, inteligência) e os contatos e informações, podem desvalorizar tal pressuposto.

Tendo em conta esta dupla perspetiva, torna-se evidente que LeE consegue mais do que complementar, flexibilizar os princípios definidos por Ravenstein, os quais continuam a influenciar o quadro analítico das migrações a várias escalas. Partindo de um estudo de caso à escala regional, procurar-se-á verificar a aplicabilidade do modelo de atracção-repulsão, tendo em conta as motivações que estiveram na base da migração destes estrangeiros em ambos os pólos da migração. 


\section{A aplicação do modelo de Ravenstein e Lee numa comunidade de imigrantes no Alto Alentejo}

\subsection{Questões metodológicas}

A escolha do território em estudo está relacionada com o fato de se tratar de uma sub-região portuguesa de baixas densidades - Alto-Alentejo (concelhos de Castelo de Vide, Marvão, Portalegre, Monforte, Arronches, Elvas e Campo Maior) - sobretudo em termos de contingente populacional ${ }^{1}$. Porém, face a um contexto marcado pelo êxodo de população jovem e pelo envelhecimento demográfico, verificou-se, em especial na última década, que um contingente significativo de estrangeiros se tem fixado nos concelhos referidos para residir, trabalhar e até mesmo para gozar o tempo da reforma.

Neste sentido, achou-se pertinente o estudo destes imigrantes, tendo sido recolhidas informações com base numa amostra de 140 indivíduos $^{2}$, a residir/trabalhar há um ano ou mais na área de estudo. Para o contexto em estudo apenas urge referir algumas informações genéricas sobre o perfil dos inquiridos, no sentido de os enquadrar na questão principal em análise. A amostra é caraterizada pela equidade de géneros, sendo a idade média de 40 anos. Trata-se na maior parte dos casos de migrações familiares, com prevalência de origens da Europa Central (Reino Unido, Países Baixos, Alemanha, etc.) e de Leste (Bulgária, Ucrânia, Moldávia, etc.), América do Sul (Brasil), África (Angola, Cabo Verde e Moçambique) e Ásia (sobretudo China). É notória a presença de dois grupos: um primeiro constituído por imigrantes laborais (Europa de Leste, América do Sul, África e Ásia); um segundo por sun-seekers (Europa Central).

Os primeiros são imigrantes mais jovens, cujo padrão familiar inclui cônjuges e filhos e a motivação de base para a migração está ligada ao emprego e à remuneração. Trabalham em diversos setores, tanto por conta própria (chineses no comércio; brasileiros em serviços estéticos ou na medicina dentária) como por conta de outrem (diversas nacionalidades na agricultura como assalariados rurais, nos serviços domésticos, na construção civil).

Os segundos são mais velhos, sendo o agregado familiar constituído na maior parte dos casos apenas

${ }^{1} \mathrm{Em} 2011$, a densidade populacional era de 28 habitantes por $\mathrm{Km}^{2}$; em Portugal, na mesma data, o valor era de 115 habitantes por $\mathrm{Km}^{2}$.

${ }^{2} \mathrm{O}$ trabalho de campo foi realizado entre Janeiro e Julho de 2010, daí a amostra ser referente aos dados mais recentes disponíveis nessa data para a escala em análise (concelho). O Instituto Nacional de Estatística (2001) indicava a existência de 726 imigrantes. A amostra representa cerca de $20 \%$ deste contingente, tendo sido recolhida através do "efeito bola de neve", o qual se constatou ser a técnica mais viável perante o contexto de estudo. pelo casal. Neste grupo não se verifica apenas a existência de reformados, como também de indivíduos em idade ativa (que estavam no auge ou no final da carreira profissional nos países de origem). Neste caso, o móbil migratório está relacionado com aspetos ligados às caraterísticas naturais (clima, paisagem, etc.) do local de destino migratório, comum aos reformados e aos sunseekers em idade ativa. Neste último caso urge afirmar que o móbil da migração também se associa ao fato de poderem desenvolver atividades laborais por conta própria, ligadas à natureza (agricultura, pecuária, agroturismo, etc.).

Foi utilizado como instrumento de recolha de informações um questionário por inquérito onde, entre outras questões, se pretendeu operacionalizar o princípio de base do modelo de atração-repulsão de Ravenstein, tendo em conta motivações ligadas ao processo migratório, na relação com os territórios de partida e de destino.

\subsection{Análise de resultados}

Tendo como objetivo perceber as motivações que estiveram na base da decisão de migrar, os imigrantes foram inquiridos sobre:

a) Motivos que estiveram na base da saída do país de origem;

b) Motivos que estiveram na base da migração para Portugal;

c) Motivos da residência no concelho onde o imigrante mora.

Sobre os fatores que interferiram na decisão de sair do país de origem são indicadas razões, sobretudo de caráter negativo.

As respostas indicam uma forte percepção negativa face ao território de partida, sobretudo no âmbito:

a) Económico e laboral, ligado aos baixos salários, desemprego, dificuldade de ascensão profissional. Assim também se corrobora o princípio da escola neoclássica, que defende o móbil das migrações com base em diferenças salariais entre regiões;

b) Estilo de vida insatisfatório (trânsito intenso nas deslocações pendulares, rígidos horários de trabalho, exigência social sobre a carreira, etc.), stress, fatores que influenciam de forma negativa a saúde dos indivíduos;

c) Insegurança, ligada à criminalidade sobre bens e pessoas ${ }^{3}$.

${ }^{3}$ Outros motivos, de caráter pessoal (desentendimentos familiares, insatisfação com o ambiente de trabalho, etc.), assim como o clima desfavorável também se enquadram nos fatores repulsivos. 
Porém há outra vertente de caráter neutral, isto é, cuja natureza não aponta repulsão pelo local de partida do migrante, mas ganha antes um caráter de desafio face ao território de destino, uma vez que se assume o desejo de aquisição de experiência de trabalho ou académica. 0 mesmo acontece com a reunificação familiar, a qual ocorre por necessidade de acompanhar o/a companheiro/a ou a família no país de chegada, não tendo sido referidos fatores negativos sobre o território de origem.
Nesta lógica, questionaram-se os inquiridos sobre os motivos da escolha de Portugal como destino migratório, tendo sido referidos diversos fatores, em especial de caráter positivo.

Embora se possam reconhecer os reflexos dos fatores atrativos, contrapondo os fatores repulsivos já indicados, há aspetos a realçar. Por um lado mantém-se a questão da reunificação familiar como sendo um móbil necessário, por isso não confere nem retira negatividade ou positividade a ambos os territórios migratórios.

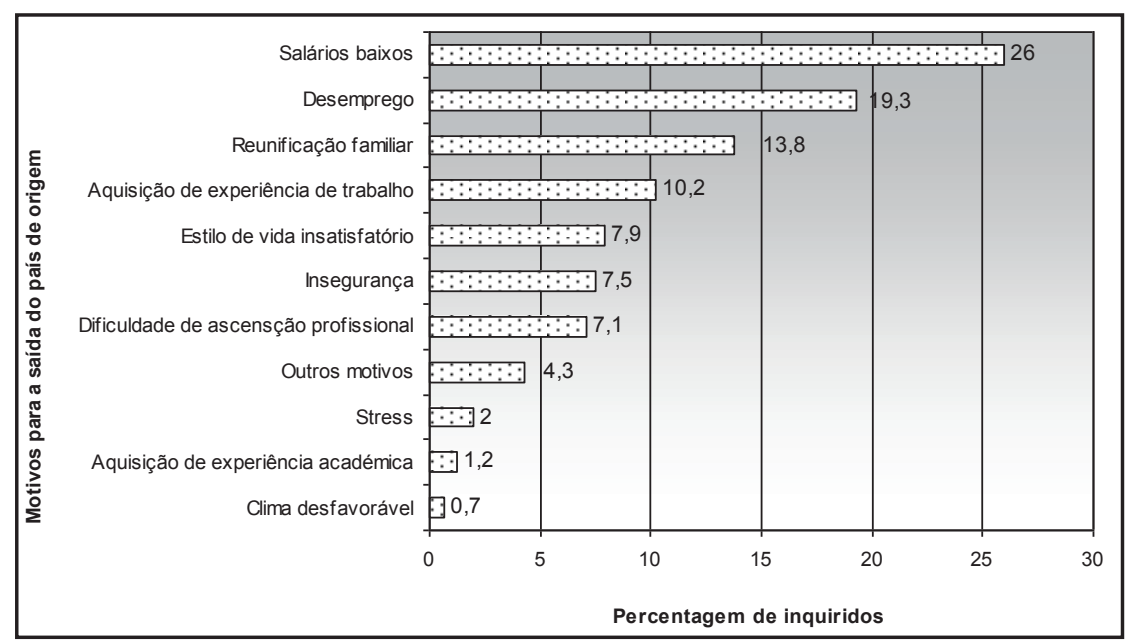

Figura 1

Motivos para a saída do país de origem

Elaboração própria (2012)

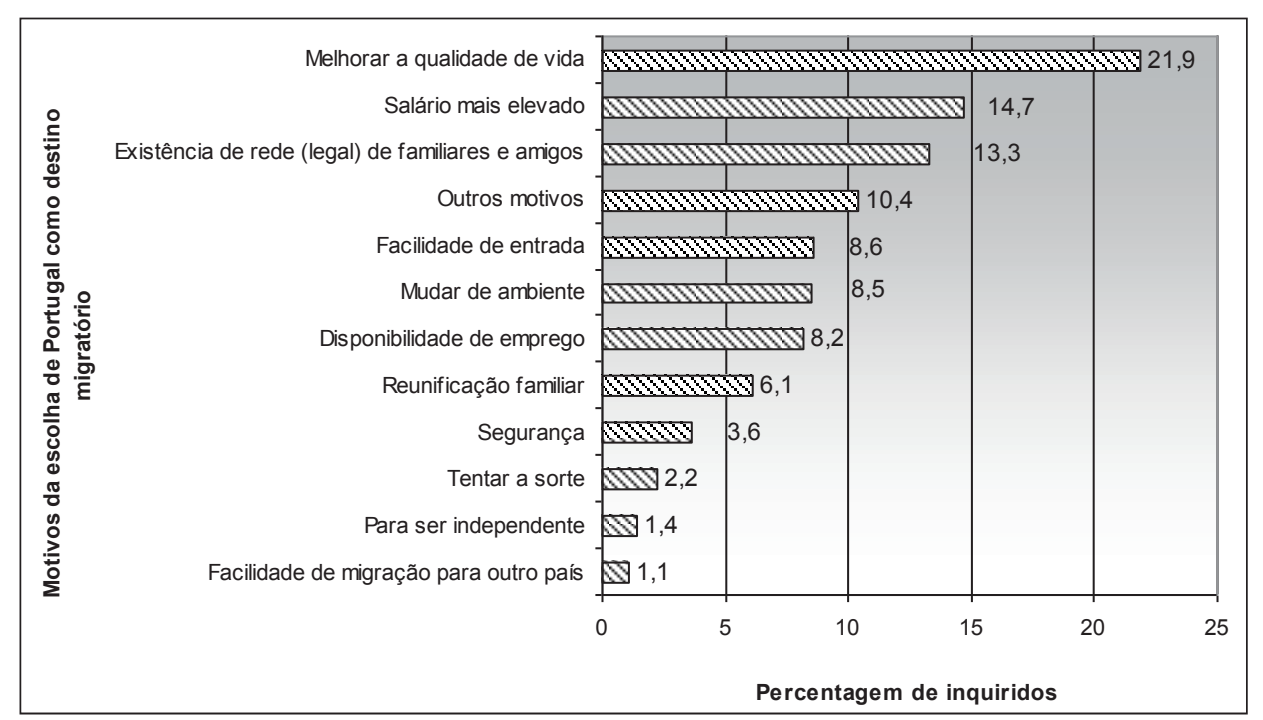

Figura 2

Motivos da escolha de Portugal como destino migratório

Elaboração própria (2012) 
Por outro o fator "acesso", embora não se revestindo diretamente de um caráter negativo, parece estar mais próximo desse pressuposto. A (suposta) facilidade de entrada no país, concebido como "plataforma" migratória, pode ser entendida como um aspeto que revela a repulsividade face a este território primeiro de migração, já que o destino final não será Portugal. Neste caso, o projeto migratório não se encontra concluído, sendo o país entendido como um ponto de passagem, quiçá com caraterísticas repulsivas similares às identificadas no local de partida, pois os inquiridos que responderam neste sentido parecem não revelar intenção de permanência.

No que concerne aos aspetos positivos, o caso dos oriundos da Europa Central (sun-seekers), referiram que a escolha de Portugal como destino migratório se pautou por considerarem que seria o país indicado para "mudar de ambiente" e para "melhorar a qualidade de vida" em termos imateriais (mais tempo livre, gestão flexível do horário de trabalho, mais oportunidades de lazer, etc.), assim como para desenvolver os seus projetos migratórios de caráter hedonista. Destacam-se ainda outros motivos apresentados, em especial a questão humana quer em termos relacionais (entendida com o a abertura e tolerância dos portugueses ao "Outro"), quer em termos de competências (capacidade dos jo- vens falarem inglês), assim como a noção de que se trata de um país onde é possível ter uma boa qualidade de vida ao nível do ritmo das atividades quotidianas (sem situações de stress), aliadas a um clima favorável (elevado número de horas de sol).

Também as questões materiais se destacam, entendidas com caráter positivo/atrativo pelos migrantes, nomeadamente a disponibilidade de emprego, salários mais elevados e valor da moeda Euro face ao país de origem. Estes aspetos corroboram os pressupostos defendidos pelas teorias das migrações já referidas, assim como questões de valorização pessoal do ponto de vista académico e psicológico associado à experimentação de uma nova realidade geográfica (ganho de independência face ao núcleo parental, tentar a sorte, mudar de ambiente).

Neste ponto há que destacar dois aspetos que, a par dos enunciados, parecem fundamentais para explicar as motivações de entrada dos imigrantes em Portugal. 0 primeiro relaciona-se com a existência de amigos/familiares que ajudaram no processo migratório, o que indica a presença de comunidades consolidadas nestes destinos migratórios, as quais já estabeleceram canais de entrada de compatriotas, como preconiza a teoria do capital social; por outro confirma a importância das redes sociais no cenário migrató-

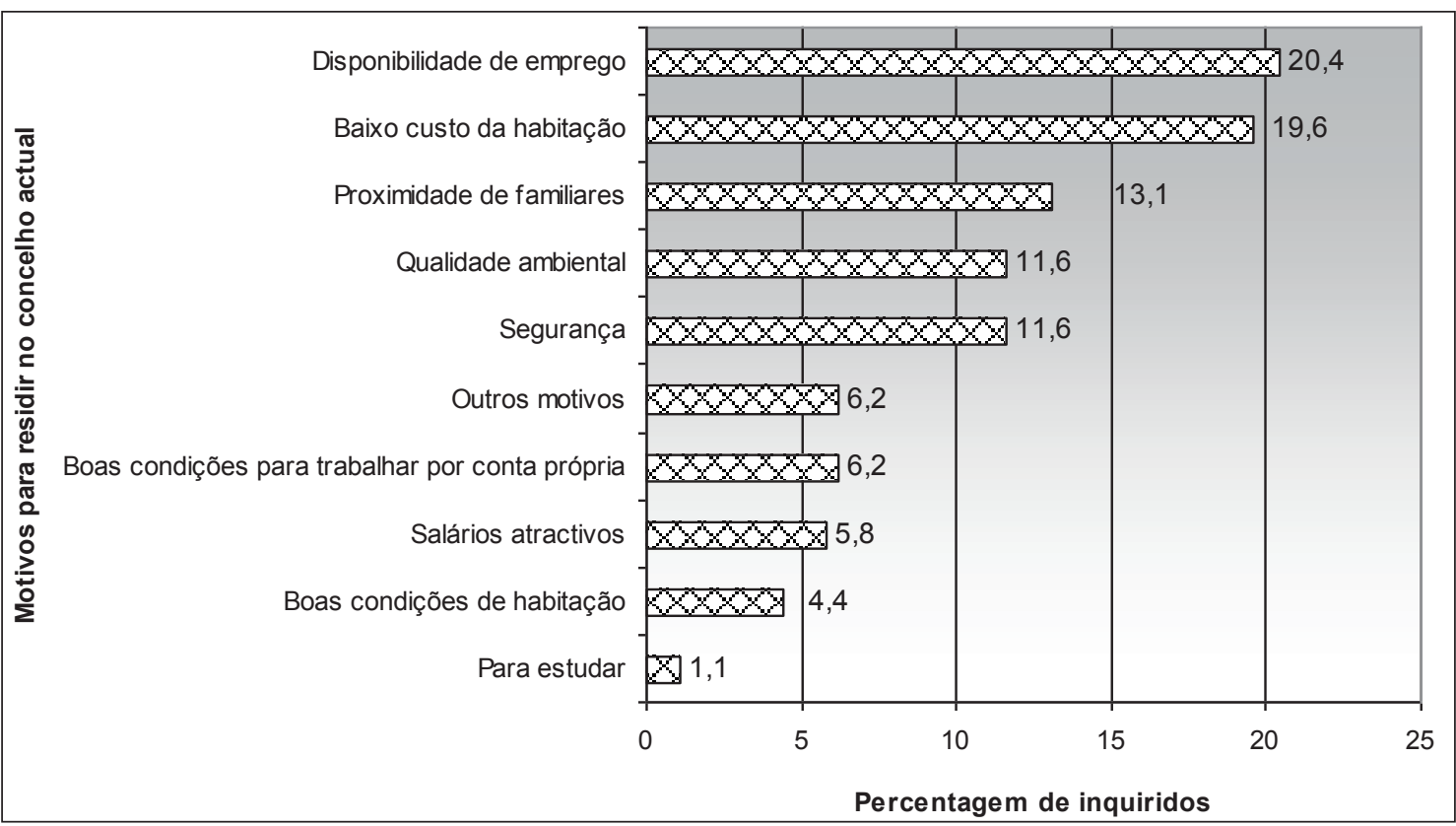

Figura 3

Motivos para fixação de residência nos concelhos em estudo

Elaboração própria (2012) 
rio internacional, que neste caso concreto é indicada como um dos fatores decisivos para a escolha deste destino migratório. É provável os inquiridos tenham ganho competências para o segundo aspeto verificado, ou seja, uma abordagem geográfica do território com maior confiança, na medida em que a maioria dos inquiridos afirmou que Portugal seria um país de "fácil entrada", sendo que alguns até consideraram a posição geoestratégica favorável, servindo como "porta de entrada para a Europa". Não quer dizer que na realidade isto tenha acontecido ou venha a ocorrer, já que os inquiridos acabaram por admitir que esta era uma ideia que tinham antes de chegar a Portugal, com base na ajuda de redes de amigos/familiares mais alargadas, estando alguns elementos noutros países da Europa. Para desmistificar esta tentativa, em muito contribuiu o fato da regularização, na maior parte dos casos, ter acarretado muitos e complexos trâmites burocráticos, acrescentando-se alguma morosidade, além das vicissitudes de estabilização da vida profissional/familiar e da eminente crise económica, fatores que abrandaram de fato esta (possível) vontade de empreender outra migração.

No que diz respeito à escala local, foram apresentados fatores decisivos para o estabelecimento da residência nos concelhos estudados. 0 primeiro indica que a vinda teve inicialmente uma forte componente laboral, ou seja, os imigrantes que se estabeleceram fizeram-no porque foi nestes concelhos que encontraram emprego. Aquando da aplicação dos questionários houve duas tendências: a que indicava que num primeiro momento a vinda deveria ter sido temporária mas que, perante a descoberta da especificidade do local (sobretudo a dinâmica rural do território), acabou por influenciar a fixação; outra onde os inquiridos previamente informados, já tiveram em consideração as oportunidades do mercado de trabalho, assim como a especificidade local (associada sobretudo às relações sociais de vizinhança e à tranquilidade humana e física para o estabelecimento da família).

Destaca-se neste contexto a segurança sentida pelos inquiridos, e que é transversal a todos os grupos estrangeiros. As cidades - Elvas e Portalegre - ainda são consideradas seguras, sentimento que aumenta nas áreas rurais onde muitos inquiridos, principalmente britânicos, neerlandeses e alemães a viver nos concelhos de Marvão, Castelo de Vide, Portalegre e Arronches, referem que é com alguma frequência que deixam portas e janelas de casa abertas, assim como chaves e na ignição dos carros durante o dia. Aliás, refira-se que o à-vontade com que o questionário foi respondido resul- tou, em todos os casos, numa visita guiada à casa/propriedade, o que demonstra a confiança na comunidade local autóctone. Os brasileiros também são outro grupo que valoriza bastante a segurança, principalmente os que são originários de grandes cidades como o Rio de Janeiro ou São Paulo.

A par da questão do emprego, encontram-se as condições favoráveis para o estabelecimento de negócio. 0 grupo asiático enfatiza esta questão na medida em que beneficia em vários aspetos: em primeiro lugar são concelhos/municípios com um aceitável potencial de clientes, face ao tipo de produtos transacionados (diversificados e de baixo custo), onde existe pouca concorrência, e além disso funcionam num modelo diferente, o que é vantajoso para os clientes (por exemplo, horários alargados todos os dias da semana); em segundo lugar, e neste sentido, a concorrência é muito mais fraca do que nas principais áreas urbanas, pelo que a reduzida dimensão do mercado de consumidores, também é secundarizada; em terceiro lugar aproveitam o fato da habitação ser mais barata em termos de arrendamento.

A questão do custo da habitação e do preço do terreno serem relativamente baixos em relação aos locais de origem tem-se assegurado como um fator decisivo na escolha destes concelhos para fixação de imigrantes, assim como a qualidade ambiental/ de vida, que é por todos associada à tranquilidade, paz, sossego, contato com a natureza e à própria abertura das comunidades locais que "acolhem" estes imigrantes.

Embora o cenário se possa generalizar à região, uma análise de cariz geográfico mais detalhada permite identificar especificidades regionais. Por exemplo nos concelhos de Marvão, Castelo de Vide, Portalegre ${ }^{4}$ e Arronches, o contingente de sun-seekers valoriza imenso a questão da qualidade ambiental, assim como o baixo preço dos imóveis/terrenos, comparados com os praticados no país de origem, assim como o clima mediterrânico e como indicam a "suavidade do Inverno" e o "elevado número médio diário de horas de sol". 0 fato da residência deste grupo de inquiridos se localizar no Parque Natural da Serra de São Mamede, também se apresenta como uma mais-valia, já que estão abrangidos pela legislação imposta pela entidade, em termos de regulamentação da construção. Como muitos referiram, é certo que não se pode mudar o traçado e a estética das habitações (pelos menos por fora) nem estabelecer todo e qualquer tipo de atividade económi- 
ca, porém têm a garantia de que "este espaço não se tornará numa cidade", como foi amplamente referido. A escolha destes concelhos para residir/trabalhar por este grupo, também esteve relacionada com a existência de uma embrionária rede social, que funcionou como geradora de informação, além de já se notar alguma atenção do mercado imobiliário neste sentido. No trabalho de campo constatou-se que uma das principais imobiliárias nacionais (Remax) contratou uma profissional inglesa (descendente de pais portugueses) para atrair e lidar com este tipo de público, além de se ter encontrado uma agência imobiliária (Extremadura Properties), cujos proprietários são um casal de neerlandeses a viver em Marvão e um autóctone a viver em Alburquerque $^{5}$ que gerem o negócio, especialmente com oferta de imóveis destinados ao segmento de mercado de imigrantes do Centro/Norte da Europa.

Em suma, pode-se constatar que, à escala local, se acentua a atratividade territorial do território de destino migratório, relacionado com as caraterísticas específicas dos lugares. Interessa verificar que um segmento de inquiridos admitiu não ter grandes expetativas positivas quanto a este local, encarando-o antes como um ponto transitório, de passagem no seu projeto migratório. Porém, o que antes entendiam como potencialmente repulsivo (por exemplo, poucas oportunidades de emprego, distância em relação aos grandes centros urbanos, pouca oferta de serviços de saúde, de educação, de lazer, etc.), veio ser contraposto por outros fatores que se revelaram atrativos (custo de vida mais baixo, por exemplo no acesso a serviços de educação, desportivos, possibilidade de não usar carro ou transportes públicos no percurso casa-trabalho, disponibilidade aceitável de bens básicos, etc.). Isto significa que a "experimentação territorial" ajudou a perceber melhor o território, sendo que as iniciais expetativas negativas não foram corroboradas e assim foi entendido um território, à partida com condições desfavoráveis, com oportunidades de interesse para a população imigrante.

\section{Conclusão}

Tendo em conta as leis enunciadas por RAVENSTEIN constata-se que, face ao caso prático estudado, urge discutir alguns pontos. 0 autor defende que, de uma forma geral, os fluxos migratórios tendem a se deslocar de áreas agrícolas para industriais, numa lógica

${ }^{5}$ Município fronteiriço da Região Autónoma da Extremadura. rural-urbana, ou seja, para grandes centros comerciais e industriais. Também refere que a população natural das cidades tende a migrar menos do que a dos campos. Neste caso tal não acontece desta forma, já que praticamente todos os inquiridos da amostra são originários de áreas urbanas dos seus países de origem, nomeadamente das cidades capitais. Além disso, atualmente residem em concelhos de índole rural, assim como nas cidades de Portalegre e Elvas, embora o façam não nas freguesias urbanas, mas antes nas rurais. Mesmo podendo trabalhar nos centros urbanos referidos, a deslocação é de curta distância/duração (cerca de meia hora), pelo que a preferência pela fixação da residência nas áreas rurais está relacionada com as caraterísticas humanas (boas relações de vizinhança, etc.), qualidade ambiental, segurança, tranquilidade, baixo preço da habitação, etc., ou seja, pelas caraterísticas particulares desses locais. Neste caso trata-se de um fluxo migratório urbano-rural, que se deslocou para uma região de baixas densidades, quer ao nível populacional, quer ao nível económico (debilidade do tecido industrial e comercial).

Além disso, e embora haja migrantes cuja deslocação foi "de curta distância" (o caso dos europeus), outros foram os que efetuaram uma migração intercontinental (o caso dos brasileiros dos chineses). Além disso, a causa das migrações não é apenas de origem económica, ganhando também um caráter hedonista por parte do grupo dos sun-seekers, que escolheu o destino da migração com base na especificidade humana e física do território (paisagem, clima, etc.).

Em alguns casos constatou-se o que Ravenstein preconiza, isto é, que a migração se processa por etapas, em especial nos que referiram não ter como principal destino migratório Portugal ou os concelhos abrangidos pelo estudo. Porém, por contingências conjunturais (crise económica) ou por decisão própria, acabaram por se deter no que seria "mais uma etapa territorial", evidenciando fatores positivos associados aos locais que se tornaram de chegada definitiva.

De qualquer forma, deve-se ter em consideração o contexto geográfico e temporal em que foi constituído o modelo, algo distante da realidade migratória atual, daí que as leis de Lee revelem uma maior proximidade ao cenário contemporâneo, assim como ao estudo de caso apresentado. Ressalve-se no entanto o fato de o autor ter assumido que os indivíduos têm mais propensão para migrar em certas fases da vida, o que se confirma, visto que é normalmente em idades mais jovens, durante a vida ativa, que ocorre o processo migratório, em especial no caso 
das migrações motivadas por questões económicas e laborais. Todavia outras formas de migração tornam este princípio discutível, por exemplo o caso das deslocações forçadas pela insegurança humana (guerra, instabilidade social e política) ou física (catástrofes naturais). No caso em estudo está presente um grupo, constituído por imigrantes da Europa Central, que efetuaram a sua migração depois de cessarem a sua vida ativa enquanto profissionais, portanto já em situação de reforma. Significa que a complexificação dos movimentos migratórios e a facilidade de deslocação de determinados grupos de indivíduos (elevados rendimentos, possibilidade de efetuarem uma migração legal) poderá vir a gerar a necessidade de se reequacionar este princípio, assim como de considerar um cenário diferente nas migrações a diversas escalas de análise.

Em suma, no que concerne aos princípios básicos do modelo de atração-repulsão de Ravenstein, concluise que se verifica uma forte influência dos fatores repulsivos, como motivação para a deslocação do território de partida. Contudo a negatividade por si pode não ser o móbil principal da saída, sendo esta apenas efetuada por uma questão estratégica, de opção, por exemplo de reunificação familiar.

Também a linearidade dos fatores atrativos do local de chegada podem ser relativos. Por um lado, o território que se constitui apenas como uma plataforma migratória provisória, ganha um caráter atrativo e constitui-se como destino final. Tal decorre da "experimentação territorial", que os inquiridos consideraram ter sido fundamental para alterar a imagem negativa do território, conseguindo identificar aspetos atrativos descobertos pelo tempo de vivência nos concelhos em causa.

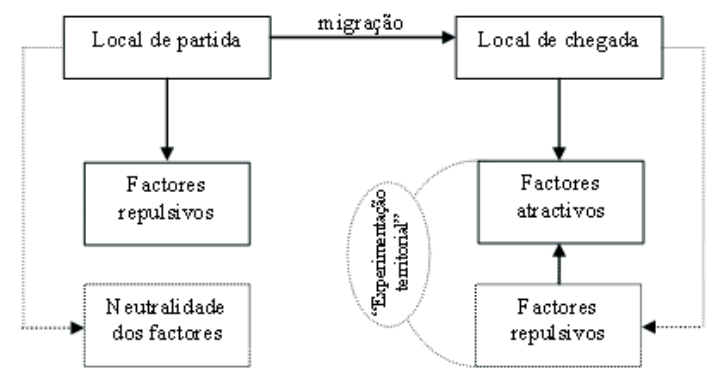

Figura 4

0 modelo de atração-repulsão: análise dos factores com base no estudo de caso

Elaboração própria (2012)

\section{Bibliografia}

Arango, Joaquin (2004) - "Theories of international migration". In: Joly, Danièle (Ed.) - International migration in the new millennium. Global movement and settlement. Ashgate, Inglaterra, pp.15-120.

Brettell, Caroline B. (2000) - "Theorizing migration in Anthropology. The social construction of networks, identities, communities and globalscapes". In BRETtelL, Caroline B.; HoluIFIELD, James F. (Ed.) - Migration theory. Talking about Disciplines. Routledge, Nova lorque, pp.97- 119.

CASTLES, Stephen (2005) - Globalização, trannacionalismo e novos fluxos migratórios. Dos trabalhadores convidados às migrações locais. Fim de Século, Lisboa.

FigueIREdo, Joana Miranda (2005) - Fluxos migratórios $e$ cooperação para o desenvolvimento. Realidades compatíveis no contexto Europeu? Alto-Comissariado para a Imigração e Minorias Étnicas, Lisboa, 118 p.

FonsECA, Maria Lucinda (2005) - Migrações e Território. Estudos para o Planeamento Regional e Urbano, CEG, $n^{\circ} 64$, Lisboa, $220 \mathrm{p}$.

KAsIMIs, Charalambos (2008) - "O novo papel dos imigrantes nas economias rurais da Europa do Sul". In: Papademetriou, Demetrios G. (Coord.) - A Europa e os seus Imigrantes no Século XXI. Fundação Luso-Americana para o Desenvolvimento, Lisboa, pp.211-242.

LEE, Everett S. (1996) - "A theory of migration". In COHEN, Robin (Ed.) - Theories of Migration. Edward Elgar Publishing Company, vol.1, Reino Unido, pp.14-24.

MASSEY, Douglas S. et al (1996) - "Theories of international migration: a review and appraisal". In COHEN, Robin (Ed.) - Theories of Migration. Edward Elgar Publishing Company, vol.1, Reino Unido, pp.181-213.

PIRES, Rui Pena (2003) - Migrações e integração. Teorias e aplicações à sociedade portuguesa. Celta Editora, Oeiras, 289 p.

PIRES, Rui Pena (Coord.) (2010) - Portugal: atlas das migrações internacionais. Tinta da China, Lisboa, $118 \mathrm{p}$.

RochA-TRINDADE, Maria Beatriz (1995) - Sociologia das Migrações. Universidade Aberta, Lisboa, $410 \mathrm{p}$.

Velez de CASTRo, Fátima (2008a) - "Imigração e Desenvolvimento Regional. Breve reflexão teórica para uma aplicação prática”. Iberografias, $\mathrm{n}^{\circ} 4$, AnolV, CEI, Guarda, pp.95108.

Velez de CASTRo, Fátima (2008b) - A Europa do Outro - A imigração em Portugal no início do séc.XXI. Estudo do caso dos imigrantes da Europa de Leste no concelho de Vila Viçosa. ACIDI - OI, Col.Teses, n¹6, 263 p. 